\title{
油井探査用光ファイバセンサ
}

\author{
山手勉 ${ }^{\dagger 1}$, Rogerio T. RAMOS ${ }^{\dagger 2}$, Robert J. SCHROEDER \\ Schlumberger-Doll Research, Schlumberger Oilfield Services, Ridgefield, CT USA
}

\section{Fiber Optics Sensors for the Exploration of Oil and Gas}

\author{
Tsutomu YAMATE, ${ }^{\dagger 1}$ Rogerio T. RAMOS,${ }^{\dagger 2}$ and Robert J. SCHROEDER \\ Schlumberger-Doll Research, Schlumberger Oilfield Services, Ridgefield, CT USA
}

(Received January 12, 2005)

\begin{abstract}
A large variety of sensors are used in the oil service industry for the exploration of oil and gas. These sensors should operate under sever conditions such as high temperature, high pressure, etc. Several fiber optical sensors have been used in the oil field industry and new fiber optical sensors are under research and development. Applications where fiber optical sensors have been successfully used and the fiber optics pressure sensors with small temperature, pressure cross sensitivity for this industry will be reviewed.
\end{abstract}

Key Words: Optical fiber, Fiber Bragg grating, Side hole fiber, Pressure sensor

1.はじめに

2010年頃までには石油可産量のMid Pointを迎えると予

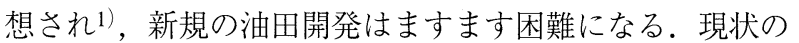
回収効率は30\%程度なため, 既存の油井で回収効率を上 げる技術が特に重要である。回収効率を最大にするに は，貯留層にセンサを埋め込み，リアルタイムで油井を 監視し，貯留層を管理するシステムが効果的である。例 えば，一本の油井は，傾斜掘削，水平掘削の技術により 地下で複数に枝分れしている. 各層は異なる油, ガス, 水の比率, 温度, 圧力等を持つため, 各層で物理量を計 測する必要がある。このような監視技術に, 航空宇宙分 野で開発されたスマートストラクチヤ技術が応用でき る2). 時分割多重や波長分割多重を用いて, 一本の光ファ イバで分布測定や複数の異なる物理量を測定し, 光ファ イバネットワークにより眝留層全体をパーマネントに監 視するシステムである. 環境に敏感な光部品や光計測器 を地上に設置し, 光ファイバセンサのみを坑井に設置す る. 従って, 高価な光部品や光計測器を複数のセンサで 共有でき，センサ単価を下げることが可能である。ま た, 油井は高温高圧 (摂氏175度，1360気圧)となるため, エレクトロニクスの信頼性が問題である．光ファイバシ ステムの場合, センサエレクトロニクスが不要なため, 信頼性の向上が期待できる.
ここでは分布型温度センサを用いた油井監視システム の応用例の紹介と, 研究開発が行われているファイバブ ラッググレーティング (Fiber Bragg Grating, FBG)の圧力 センサに関して解説する。

\section{2. 分布型温度センサ}

油井で使われている分布型センサにラマン散乱を利用 した分布型温度センサがある (Distributed Temperature Sensor, DTS $)^{2)}$. 光ファイバの片端から光パルスを入射す ると, 光パルスはファイバ中を伝搬しながら散乱を生 じ, 減衰していく. 散乱光の内, ラマン散乱光は波長が 若干シフトし，短波長にシフトした光(反ストースク光)の 強度は温度により大きく変化するので, 光ファイバの温 度がわかる．また，位置情報は散乱光が入射端に戻るま での時間を測定すれば，散乱を生じた位置を特定でき る．測定間隔は光のパルス幅で決まる。このようにし て, 分布型温度センサは $1 \mathrm{~m}$ 間隔で数キロ以上に渡り連続 的な温度測定ができる。

石油探査の分野では, 例えば水蒸気圧入法 (steam flooding)の際の温度分布測定に用いられている ${ }^{3)}$. 水蒸気圧入 法は石油層に熱エネルギーを与えることにより原油の粘 度を下げて採収率を増加させる方法である．圧入された 水蒸気の移動分布や生産井に到達する現象を坑内の温度

\footnotetext{
†1現在の所属：シュルンベルジェ(株)（† 229-0006 神奈川県相模原市淵野辺2-2-1）

${ }^{\dagger}$ Present Address: Schlumberger K. K., 2-2-1 Fuchinobe, Sagamihara, Kanagawa, 229-0006 Japan

${ }^{\dagger}$ Present Address: Sensa Schlumberger, Gamma House, Chilworth Science Park, Southampton, Hampshire, SO16 $7 N S$, UK
} 
分布を連続的に測定する事により監視する事ができる.

Fig. 1は水蒸気圧入の監視井戸の分布型温度測定の例で ある．注入井戸からの水蒸気圧入後，下位の2砂岩層は圧 入直後から温度上昇が観測され，その後水蒸気が到達し ている。一方，上位の1砂岩層は 15 个月後水蒸気圧入が観 測されている。

シュルンベルジェ社では300以上の油井に分布型温度セ ンサを設置しており，分布型温度センサはオイルフィー ルドで広く使われている。

\section{FBGを用いた圧カセンサ}

\section{1 スタンダードファイバ}

ファイバブラッググレーティング $(\mathrm{FBG})$ 技術は光通信の 分野で応用されているが，センサとしても優れた特徴を 持っている. FBGは小さく，歪みに対する優れた線形性を 持ち，波長分割多重や時分割多重を用いて分布計測がで きるため，貯留層全体をパーマネントに監視するシステ ムへの応用が期待されている. FBGは波長選択性を持つ反 射鏡の役目をする.FBGの波長は温度や圧力等の外部から の物理量の作用を受けてシフトするため，物理量に比例 した信号が得られる2)。シュルンベルジェ社では，高温高 圧下の分布計測用のセンサとしてFBGを用いたセンサの研 究を行っている。

Fig. 2 は異なる温度における，スタンダードのシングル モードファイバを用いたベアFBGの圧力応答を示す ${ }^{4)}$ 。静 水圧下のベアFBGの圧力感度は小さく約 0.03 pm/psi (pound per square inch, 1 気圧 $=14.7$ psi）で，例光ば計測器が 0.2 $\mathrm{pm}$ の分解能を持つ場合, 約 $7 \mathrm{psi}$ (0.5気圧)の圧力变化が測 定できる。この值はシュルンベルジェ社の圧力センサ Crystal Quartz Gaugeの特性 (分解能 < 0.01 psi, ドリフト $<1 \mathrm{psi} /$ year $^{5)}$ に比べて劣っている。 さらに, ベアFBGの 温度感度は約 $8 \mathrm{pm} /{ }^{\circ} \mathrm{C}$ なで, $7 \mathrm{psi}$ の圧力計測のためには $0.03{ }^{\circ} \mathrm{C}$ のンサ温度をモニタする必要がある。

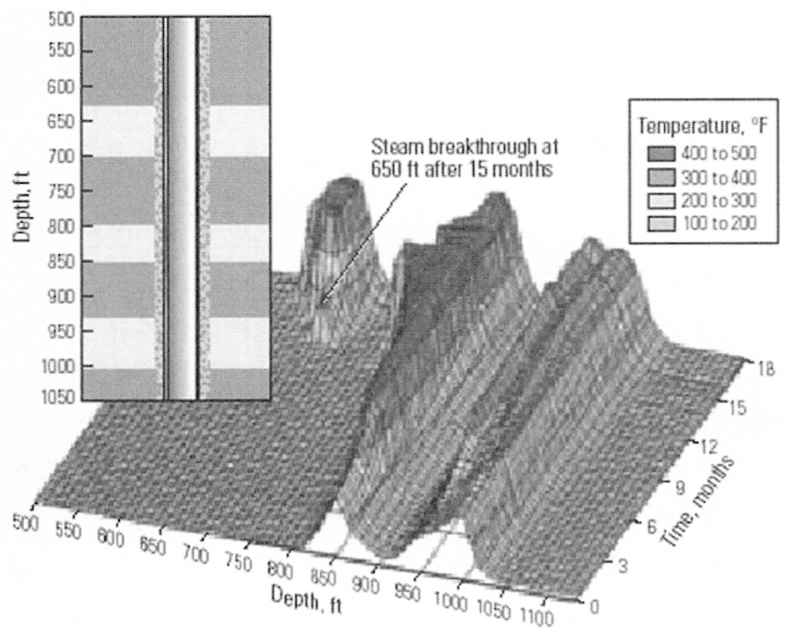

Fig. 1 Fiber-optic temperature monitoring in steamflood observation well. DTS system detected steam breakthrough in the top sand after 15 month.

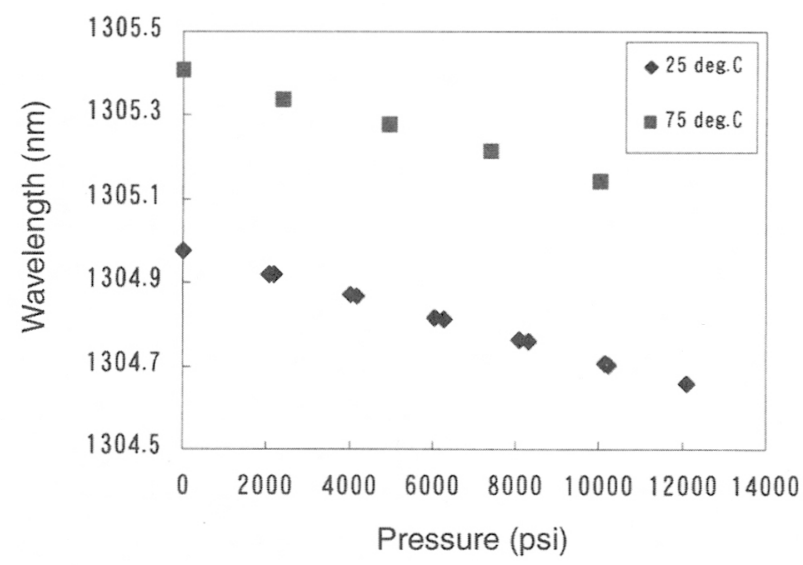

Fig. 2 Response of a bare Fiber Bragg grating with pressure and temperature.

3.2 サイドホールファイバ

シュルンベルジェ社では, 高感度で, しかも, 温度 . 圧力のクロス感度の小さい圧力センサを目的に，サイド ホールファイバや偏波面保存ファイバを用いたFBG圧力セ ンサを研究している4).

Fig. 3，Fig. 4にサイドホールファイバの断面と 13 psi (0.9 気圧)，7891 psi(537気圧)でのスペクトルを示す。サイド ホールファイバ径とサイドホール径はそれぞれ $125 \mu \mathrm{m}$, 35 mである. 13 psiではシングルピークであるが， 7891

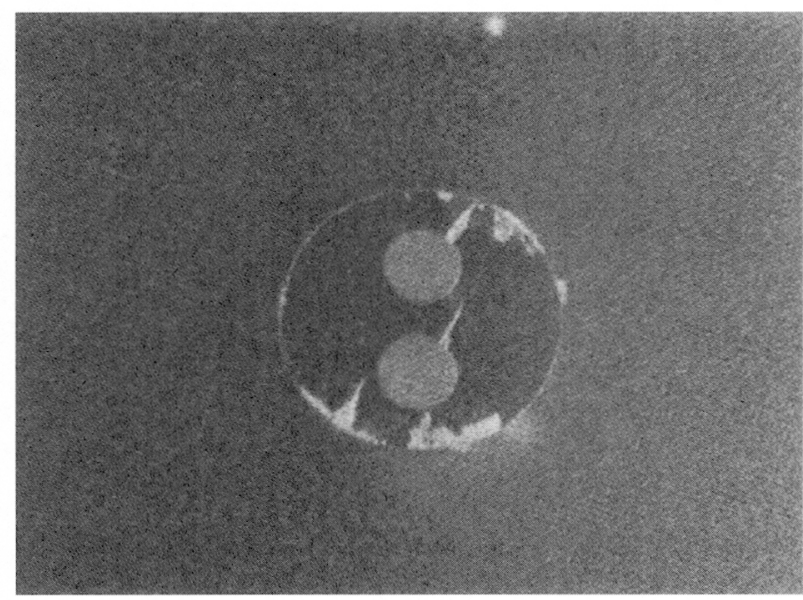

Fig. 3 A photograph of the side hole.

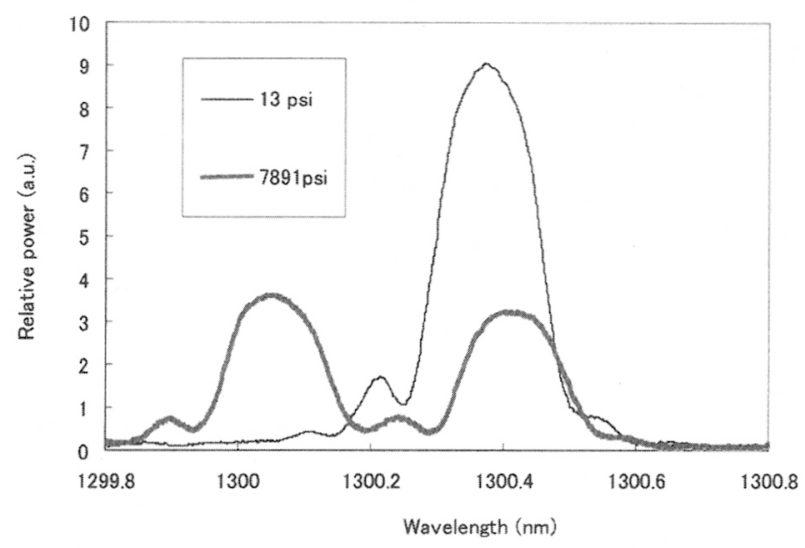

Fig. 4 Response to pressure. 
psiではデュアルピークとなる。これは, 高圧下で, サイ ドホールにより横方向に応力差が生じ, そのため複屈折 が生ずるためである．圧力值はデュアルピークの間隔を 測定することで得られる。相対值測定なので, シングル ピークの絶対值測定に比べ，高精度が期待できる。さら に, 温度変化により, 各ピークは同じように変化するた め，圧力測定への影響を少なくできる。

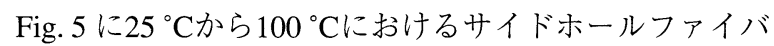
を用いたFBGセンサの圧力応答を示す。圧力応答の温度依 存性はほとんどなく, 温度 ·圧力のクロス感度は標準の ファイバを用いたFBGセンサに比べ2桁程度改善されてい る。この特性は油井のような温度が変化する環境下での 圧力計測では特に重要である. 圧力感度も改善し, 約 1.7 倍に増えているが十分ではない。

\section{3 機械的な圧力感度増幅}

温度 ·圧力のクロス感度を小さく保ち, しかも高感度 なファイバ圧力センサは，ファイバに側圧力のみを与え る機械的な増幅機構をもつトランスデューサーで実現で きる。この方法を用いて，スタンダードのファイバを用 いた場合でもデュアルピーク特性をもつFBG圧力センサが 可能になった6).

Fig. 6は圧力トランスデューサーである.ファイバへ側 圧はトランスデューサーのピストンにより与えられ，ピ ストンの表面積に比例する。プロトタイプは $1 / 4$ ”直径のピ ストンを用いた。 圧力はピストン表面に置かれた薄いス テンレス製のダイアフラムとOリングによりシールされて いる. 皮膜を取り除いた2本のファイバは2枚の石英板の 間にセットされている。一本にはFBGが書き込まれ，もう 一方のファイバはダミーファイバとして上下の石英板の 均衡を保つように配置されている。ファイバ自体は高圧 環境下にさらされていないため, 高温高圧のファイバ フィードスルーは不要である。

ピークセパレーションは以下のように解析できる7,8).

ファイバへの側圧は以下の関係式でコアに応力を与え る.

$$
\sigma_{x x}=-\frac{2 F}{\pi h D}
$$

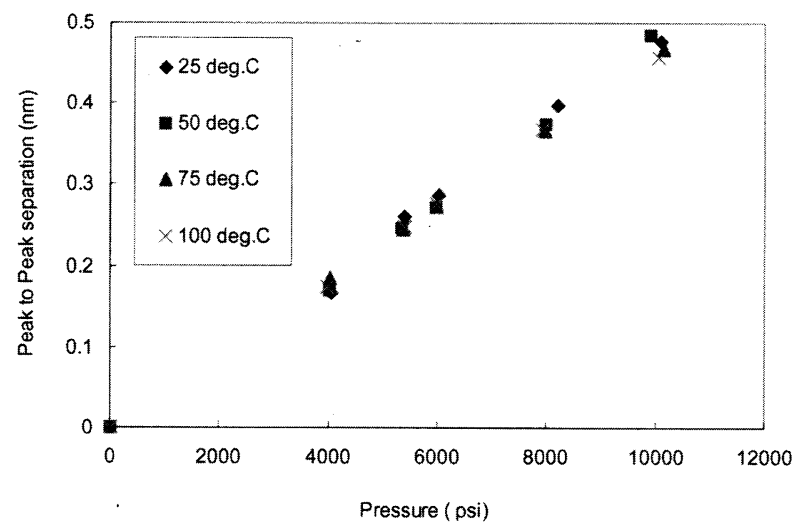

Fig. 5 Response of side hole FBG with pressure and temperature.

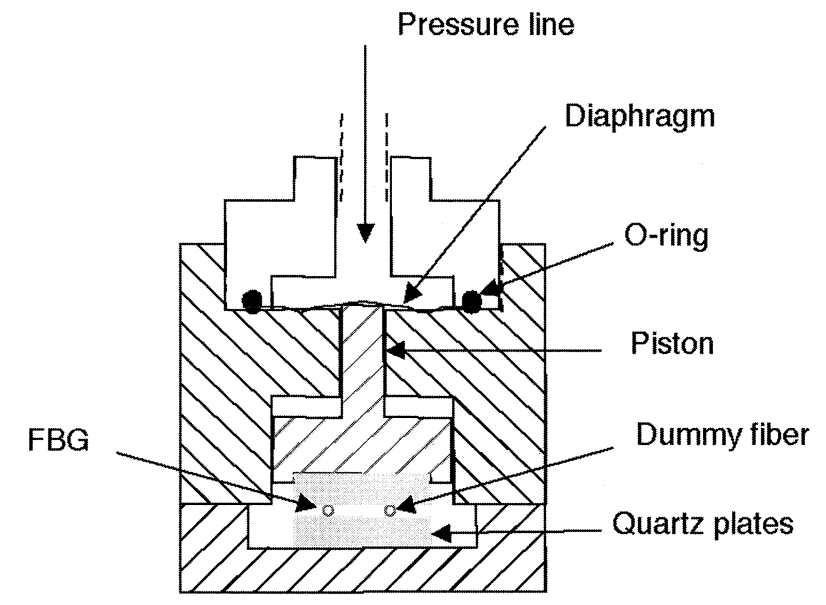

Fig. 6 Structure of transversely loaded Bragg grating pressure transducer.

$$
\sigma_{y y}=-\frac{2 F}{\pi h D}
$$

ここで

$D ：$ ファイバの直径

$h:$ 側圧長

$F:$ 側圧

この応力により生ずるコアの歪は下記の式で表される。

$$
\begin{aligned}
& \varepsilon_{x x}=\frac{1+v}{E}\left\{\sigma_{x x}(1-v)-v \sigma_{y y}\right\} \\
& \varepsilon_{y y}=\frac{1+v}{E}\left\{\sigma_{y y}(1-v)-v \sigma_{x x}\right\}
\end{aligned}
$$

ここで

$E:$ ヤグ率

$v:$ ポアソン比

これらの歪によって生ずる波長の変化は以下の通りであ る.

$$
\begin{aligned}
& \frac{\Delta \lambda_{x}}{\lambda_{x}}=-\frac{1}{2} n_{0}^{2}\left\{P_{11} \varepsilon_{x x}+P_{12} \varepsilon_{y y}\right\} \\
& \frac{\Delta \lambda_{y}}{\lambda_{y}}=-\frac{1}{2} n_{0}^{2}\left\{P_{11} \varepsilon_{y y}+P_{12} \varepsilon_{x x}\right\} \\
& \text { ここで }
\end{aligned}
$$

$\Delta \lambda: \mathrm{FBG}$ 波長シフト

$\varepsilon:$ 歪係数

$P:$ 歪光学係数

$n_{\mathrm{o}}$ : 屈折率

スタンダードファイバの場合， $13 \mathrm{~N} / \mathrm{m}$ の側圧により約 1 $\mathrm{pm}$ のピークセパレーションが生じる.

Fig. 7 は圧力とピークセパレーションの関係を示してい る。実線は理論值であり，点は実験值である。実験值は 理論値に一致している.

ピークセパレーションの圧力感度は〜 $0.33 \mathrm{pm} / \mathrm{psi}$ であ り, この值は静水圧下のスタンダードFBGの圧力感度 $($ 一 $0.03 \mathrm{pm} / \mathrm{psi}$ ) に比べて10倍改善されている. 例えば, $0.2 \mathrm{pm}$ の分解能を持つ計測器の場合, $0.6 \mathrm{psi}$ の圧力变化が測定で きる。

Fig. 8にピークセパレーションの各温度における圧力依 存性を示す。ピークセパレーションは線形の圧力特性を 


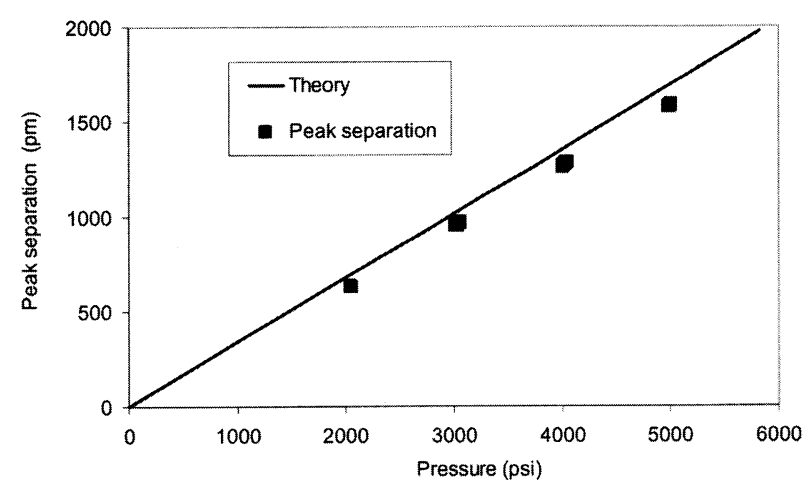

Fig. 7 Pressure sensitivity. Experiment and calculation.

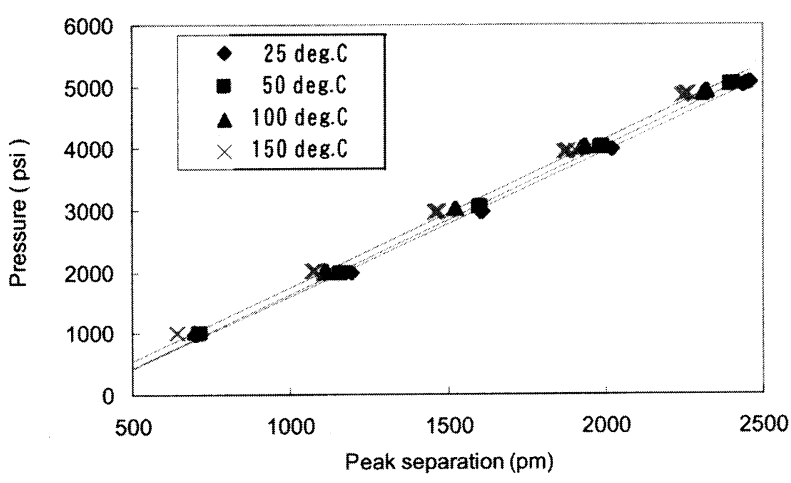

Fig. 8 Peak separation versus pressure at different temperatures.

各温度で示している。また，ピークセパレーションの温 度依存性はきわめて少ない. 残留温度依存性は各ピーク の絶対値を用いて補正できる。

\section{4 ピークスペクトラム分離技術}

Fig. 7では2000 psi以下の圧力は計測していない.これは 低い圧力の条件ではピークセパレーションが狭くなり, さらに圧力を下げていくと各ピークが重なり合い，通常 の測定方法ではピークセパレーションを計測できないた めである。この問題は光の偏光特性を用いて，各ピーク を別々に読み出す方法で解決できる9). 各ピークは異なる 偏光特性を持つので，その偏光特性のみを持つ光を入射 することで，重なり合ったピークを別々に測定すること ができる. Fig. 9, Fig. 10に実験結果を示す.

$$
\text { 4. まとめ }
$$

分布型温度センサを用いた油井監視システムの紹介 と，ファイバブラッググレーティングの圧力センサに関 して解説した。分布型温度センサはそのユニークな特徵 (連続的な測定, 省スペース, 高温動作等)を生かして, 水 蒸気圧入の温度監視等に応用されている，温度 ·圧力の クロス感度の小さいデュアルピークを持つFBG圧力センサ は，静水圧下のサイドホールファイバ，偏波面保存ファ イバや，ファイバに側圧を与えるトランスデューサーを 用いて実現できる。トランスデューサーを用いた場合， 圧力感度は10倍改善し, サブpsiレベルの圧力変化の測定

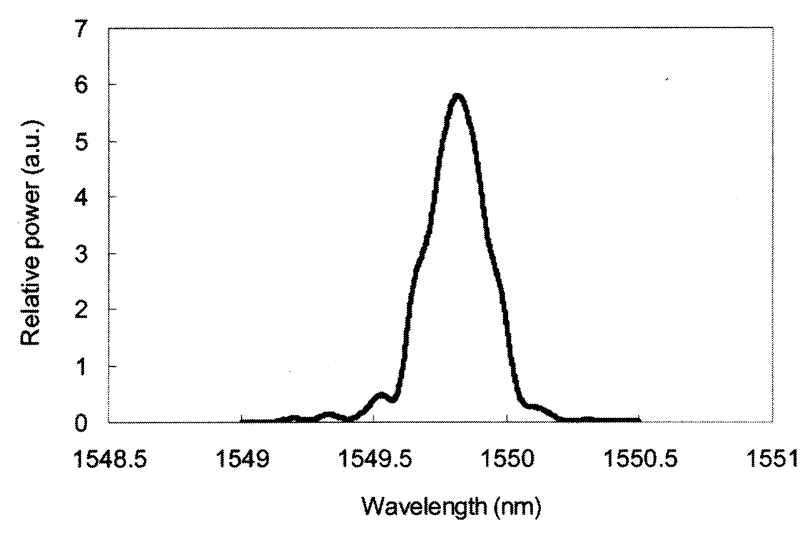

Fig. 9 Dual peak spectrum before polarization control. Dual peak spectrum is overlapped.

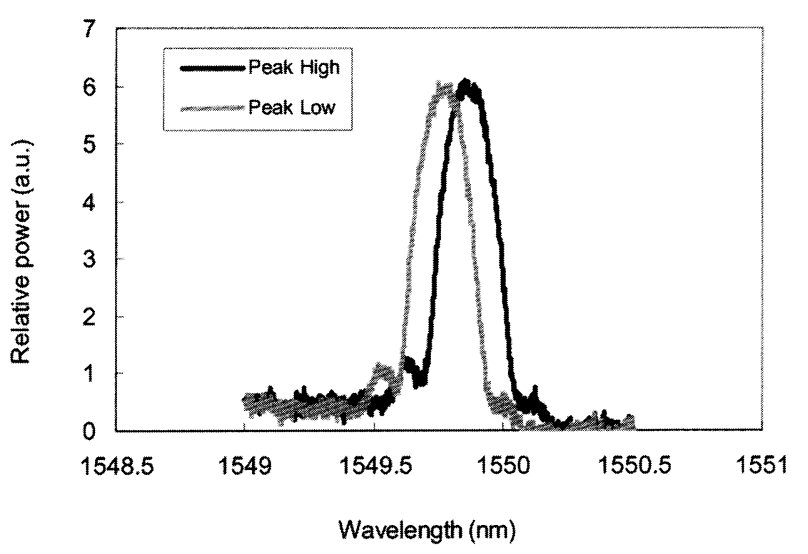

Fig. 10 Dual peak spectrum after polarization control. Each spectrum is separated.

が可能になった.

光ファイバや光技術を用いた油井への応用例は，地層 間隙流体光分析装置 ${ }^{10)}$ ，光振動センサ11)，光プローブ(混 相流検出器) ${ }^{12}$ ), 油井用光ケーブル13) 等も実現されてい る.このような光センサの成功例から考え, 今後, 油井 でより高度な計測やパーマネント油井監視システム等へ 光技術が応用されていくこととなろう。

\section{参考文献}

1) C. J. Campbell and J. H. Laherrere: Scientific American (March, 1998) 78.

2) E. Udd Editor: Fiber Optics Smart Structures (Wiley-Interscience Publication, NewYork, 1995).

3) C. Curtis, R. Kopper, E. Decoster, A. Guzmán-Garcia, C. Huggins, L. Knauer, M. Minner, N. Kupsch, L. Linares, H. Rough, and M. Waite: Oilfield Review Autumn (2002) 30.

4) R. J. Schroeder, T. Yamate, and E.Udd: Proceedings 13th International Conf. On Optical Fiber Sensors, SPIE vol. 3746 (April, 1999) p. 42.

5) T. Yamate, R. T.Ramos, R. J. Schroeder, and E.Udd: Proceedings 15th International Conf. On Optical Fiber Sensors, SPIE vol. 3746 (May, 2002) p. 535.

6) N. Matsumoto, Y. Sudo, B. K. Shinha, and M. Niwa: IEEE Transaction on Ultrasonic, Ferroelectrics, and Frequency Control, Vol. 47 (2000) 346.

7) R. B. Wagreich, W. A. Atia, H. Singh, and J. S. Sirkis: Electron. Lett. 32 (1996) 1223.

8) C. M. Lawrence, D. V. Nelson, A. Makino, and E. Udd: Proceedings of SPIE, Vol. 3180 (1997) p. 42. 
9) T. Yamate, R. T. Ramos, R. J. Schroeder, and E. Udd: Proceedings 16th International Conf. On Optical Fiber Sensors (ISBN 4-89114036-4, 2003) p. 64.

10) T. Terabayashi, T. Yamate, G. Fujisawa, O. Mullins, S. Betancourt, C. Dong, A. Carnegie, and T. Torgersen: SPWLA Japan Chapter, The 9th Formation Evaluation Symposium of Japan (September) p. 1 .
11) K. Nishida and M. Kondo: Sensors and Actuators A21-A230 (1990) p. 445.

12) R. T. Ramos and E. J. Fordham: J. Lightwave Technol. 17 (1999) 1392.

13) Sonde Off Magazine (Schlumberger publication) vol. 37 July/August (1985) p. 14. 